Ciência eNatura, Santa Maria, v. 37 n. 4 set-dez. 2015, p. 555-563

Revista do Centro de Ciências Naturais e Exatas - UFSM

ISSN impressa: 0100-8307 ISSN on-line: 2179-460X

\title{
ciênciaenatura
}

\section{Inventário de inundações registradas na área urbana de Santa Cruz do Sul entre os anos de 1980 e 2013}

\author{
Flood records in the urban area of Santa Cruz do Sul between the years 1980 and 2013 \\ Daniel Junges Menezes ${ }^{1}$, Luís Eduardo de Souza Robaina² e Romario Trentin ${ }^{3}$

\begin{abstract}
${ }^{1}$ Doutorando em Geografia, PPGGeo, Universidade Federal de Santa Maria, Santa Maria, Brasil 2Doutor, Departamento de Geociências, Universidade Federal de Santa Maria, Santa Maria, Brasil ${ }^{3}$ Doutor, Departamento de Geociências, Universidade Federal de Santa Maria, Santa Maria, Brasil
\end{abstract}

\section{Resumo}

O conhecimento da periodicidade, recorrência, ou até o aumento da severidade de processos ao longo do tempo, são elementos importante no diagnóstico e na implementação de ações mitigadoras. O objetivo deste trabalho é apresentar um inventário das inundações ocorridas no período compreendido entre 1980 a 2013 em Santa Cruz do Sul, município localizado na porção centro - leste do estado do Rio Grande do Sul. Como fontes foram utilizados o inventário realizado por Reckziegel (2005), o Banco de Dados de Registro de Desastres / Secretaria Nacional de Defesa Civil - SNDC a Defesa Civil do Rio Grande do Sul e ainda jornais de circulação regional. O levantamento apontou trinta e três registros de inundações no período de análise, sendo mais significativas nos meses de verão. Além disso, o inventário permitiu identificar a presença de problemas atrelados às inundações em pelo menos 22 bairros em diferentes porções da área urbana do município.

Palavras-chave: Desastres naturais; Análise temporal; Inundações urbanas.

\section{Abstract}

The knowledge of periodicity, recurrence, or even increasing severity of causative processes over time damage, are important elements in the diagnosis and implementation of mitigation actions. This paper present an inventory of the floods in the period from 1980 to 2013 in Santa Cruz do Sul, a city located in the central portion Centre-East of the Rio Grande do Sul state. As sources were used inventory held by Reckziegel (2007), the Bank of Registration Disaster Data da Secretaria de Defesa Civil Nacional - SNDC, the Defesa Civl of Rio Grande do Sul state and newspapers. The studies showed thirty-three records of floods being more significant in the summer months. Besides the inventory identified the presence of problems linked to flooding in at least 22 neighborhoods in different parts of the urban area of the municipality.

Keywords: Natural disasters; Temporal analysis; Urban floods. 


\section{Introdução}

0 s desastres naturais, gradativamente, têm ganho maior atenção das comunidades em geral, seja na sociedade civil, ou por meio dos gestores públicos e pesquisadores do tema, em função do aumento do registro de frequência e intensidade, como também, da severidade dos eventos adversos e, consequentemente, perdas ocasionados pelos mesmos. Dados do Emergency Events Database EM-DAT, apresentados na Figura 1, apontam para um crescimento no número de registros de desastres naturais no mundo no período compreendido entre meados dos anos 70 até o início deste século.

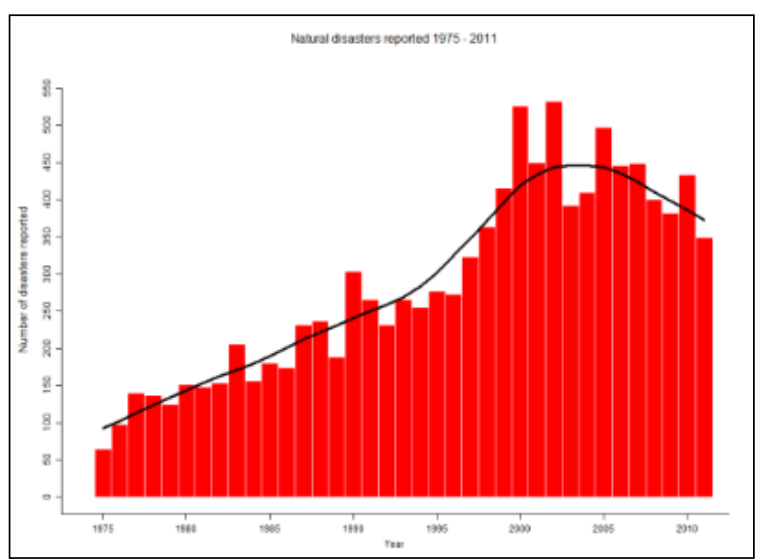

Figura 1: Desastres naturais registrados no mundo entre 1975 e 2011 pelo EM - DAT. Fonte: www.emdat.be.

O crescimento do número de registros se dá em função de elementos que interagem entre si, como aumento geral da população global e o aumento das populações em situação de domicílio urbano, o que remete a exposição de um número maior de pessoas e um maior número de afetados.

Somam-se a isto, as mudanças climáticas e ambientais em diferentes escalas, a consolidação de um modelo econômico excludente e caracterizado por marcantes desigualdades sociais, que tem contribuído para o acréscimo no contingente populacional em situação de risco. Deve-se apreciar, ainda nesta análise, a maior difusão dos acontecimentos associados ao tema (sob as mais variadas óticas) e o avanço tecnológico e informacional que se deu durante as últimas décadas, em contraponto ao fato de que muitos eventos no pretérito não eram registrados e, consequentemente, não contabilizados.

Veyret (2007), entretanto, destaca que o aumento do número de registros e principalmente a frequência e intensidade dos eventos e então imputação, cada vez mais, da presença do risco em nossas sociedades, está associada antes de tudo, à atribuição à natureza uma responsabilidade que poderia ser creditada a própria sociedade, que por ação do de alguns atores que envolvem desde o poder público, os agentes imobiliários, e a própria população afetada, fazem com que os desastres sejam vestidos de certo fatalismo, o que lhes atenua responsabilidades.

Da mesma forma, Robaina e Trentin (2013) salientam que a percepção de aumento da frequência e da intensidade de desastres, na segunda metade do século passado, não pode ser atribuída inteiramente ao incremento da magnitude e constância de eventos naturais adversos, mas, em grande parte, à ocupação extensiva do espaço geográfico sem que haja observância das dinâmicas naturais locais.

No Brasil, os processos associados à dinâmica fluvial tem grande importância na caracterização da ocorrência de desastres. Somente ano de 2012, conforme aponta o Anuário Brasileiro de Desastres Naturais (BRASIL/ CENAD, 2012), foram contabilizados 16.977 .614 de pessoas afetadas por desastres naturais no país, onde mais de $40 \%$ deste montante, estão associados à ocorrência de desastres registrados como inundações e enxurradas.

Em espaços caracterizados pela ocorrência de alguns processos que remetem à perdas econômicas e sociais, tal como as inundações, o conhecimento da periodicidade, recorrência, ou até o aumento da severidade deste processo ao longo do tempo, são elementos importante no diagnóstico e na implementação de ações mitigadoras.

Sob este escopo, o objetivo deste trabalho é apresentar um inventário das inundações ocorridas no período compreendido entre 1980 a 
2013 na área urbana do município de Santa Cruz do Sul, localizado na porção centro - leste do estado do Rio Grande do Sul (Figura 2). Estando o município posicionado à margem esquerda do Rio Pardinho, são recorrentes as inundações causadas por este e também por seus tributários na área urbana.

\section{Pressupostos Teóricos}

Bertê (2004) aponta as inundações periódicas como um dos principais problemas ambientais no estado do Rio Grande do Sul. Para a autora, o agravamento dos problemas associados ao extravasamento dos leitos normais dos cursos d'água está ligado a remoção da mata ripária e consequente assoreamento. Além disso, a ocupação das planícies de inundação por assentamentos humanos, em especial, os com técnicas construtivas inadequadas, fazem que o extravasamento das águas do canal fluvial, um integrante da dinâmica hídrica natural, seja encarado como uma anomalia e cause prejuízos.

No que refere à evolução dos desastres, as inundações vão estar incluídas na classe de evolução súbita ou aguda, que comporta desastres de natureza cíclica e caráter sazonal e que podem, em alguns casos, ser previstos em função do período de chuvas. Quanto à origem estão na classe dos hidrológicos ou ainda hidrometereológicos, devido ao fato de que geralmente o evento desencadeador de uma inundação está associado a incrementos de precipitação (CASTRO, 2003).

Com o intuito de atualização e também simplificação, sob o contexto do novo COBRADE - Classificação e Codificação Brasileira de Desastres (2012), as inundações passam a se enquadrar no grupo dos desastres hidrológicos (ao lado de enxurradas e alagamentos).

Kobiyama (2006) ressalta que existe uma grande divergência entre os cientistas sobre as definições a serem adotadas devido as diferentes percepções e terminologias utilizadas para as inundações, havendo uma dificuldade em padronizar as categorias das mesmas. Isto nem sempre é devido à falta de conhecimento, mas sim, devido à dificuldade de identificação do fenômeno em campo e à ambiguidade das definições existentes. Por sua vez, Amaral \& Ribeiro (2009, p.41) definem inundações e enchentes como "eventos naturais que ocorrerem com periodicidade nos cursos d'agua, frequentemente deflagrados por chuvas fortes e rápidas ou chuvas de longa duração".

Recentemente, também contextualizado ao COBRADE (2012) a Defesa Civil, passa a considerar somente "inundações" e "enxurradas", para eventos que marcam o extravasamento da água em direção ao leito maior, em detrimento do uso da palavra enchente (que remetia a inundações graduais).

Em ambos os conceitos e a sua aplicabilidade pelos referidos autores, as inundações são eventos que indicam o processo de avanço da água sobre do leito maior ou planície de inundação do rio, extravasando portanto, a capacidade de escoamento do canal principal, devido geralmente a incrementos de precipitação e remetem a processos associados à dinâmica fluvial.

\section{Metodologia de Trabalho}

O levantamento temporal das inundações ocorridas nas últimas décadas compreendeu o período de 1980 a 2013 (este último ano incluso em função dos eventos ocorridos na etapa de conclusão do trabalho, sendo úteis para validação dos dados). Este trabalho utilizou o inventário realizado por Reckziegel (2007) onde são computados dados até o ano de 2005 e seguiu a partir do que é disponibilizado pelo Banco de Dados de Registro de Desastres / Secretaria Nacional de Defesa Civil - SNDC e pela Defesa Civil do Rio Grande do Sul e ainda jornais de circulação regional. Este segundo grupo de informações faz menção a data e local dos eventos. A consulta à Defesa Civil municipal de Santa Cruz do Sul, com sede no município, permitiu estabelecer uma caracterização de caráter espacial das áreas onde as inundações são mais recorrentes.

Utilizou-se o software Microsoft Office Excel 2010 na compilação das informações e o software ArcGIS 10, desenvolvido pela ESRI, para estruturar o banco de dados georreferenciados que serviu de base para a geração do mapa com os bairros afetados. A base cartográfica se deu a partir do mapeamento temático de 2011 elaborado pela Divisão de Geoprocessamento da Prefeitura Municipal de Santa Cruz do Sul e da base vetorial e disponibilizada pela mesma, em escala 1:10.000. 


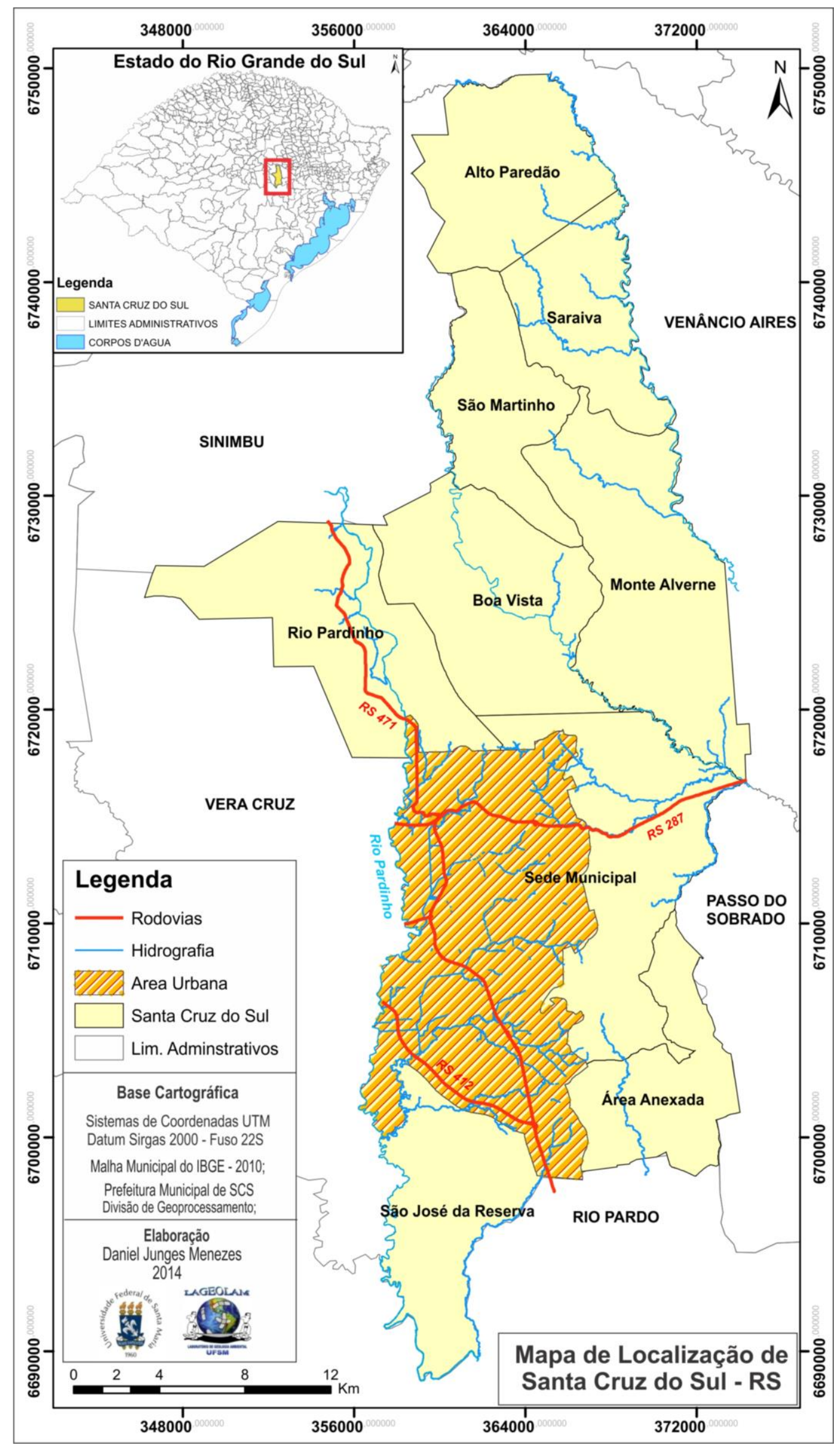

Figura 2: Mapa de localização de Santa Cruz do Sul. Organização do autores. 


\section{Resultados}

As áreas consideradas sujeitas a inundações são expressivas e se encontram na porção mais a oeste da área urbana, principalmente, associadas à extensa planície de inundação do rio Pardinho e, também, áreas próximas aos seus afluentes, os arroios Jucuri, Lajeado, Preto, Das Pedras, Levis Pedroso. Destacam-se os bairros Várzea, Dona Carlota, Rauber, Arroio Grande, Progresso, Santa Vitória, Faxinal do Menino Deus, e Renascença, com registros constantes.

Foram verificados problemas associados a inundações em áreas adjuntas ao arroio Lajeado no bairro Renascença, que fica mais ao norte da área urbana, próximo a $B R$ 287, que tem motivado a presença de intervenções individuais de mitigação em algumas residências.

Em uma área alocada entre a BR 471 e o rio Pardinho (Figura 3), encontramos os bairros Várzea e Santuário, afetados por inundações, que posicionados em uma área naturalmente muito suscetível, não contam com a BR 471, que atua com um "dique", a exemplo dos bairros e Schulz e Bom Jesus, que estão posicionados a leste da rodovia e que indicaram em um primeiro momento, apresentarem menores problemas em relação às inundações. Tendo a sua origem na incorporação de antigas áreas rurais e de veraneio, o bairro Várzea apresenta no extremo oeste uma localidade chamada Navegantes ou ainda Prainha, que figura-se hoje como ocupação permanente, tornando os problemas associados à inundações registros constantes.

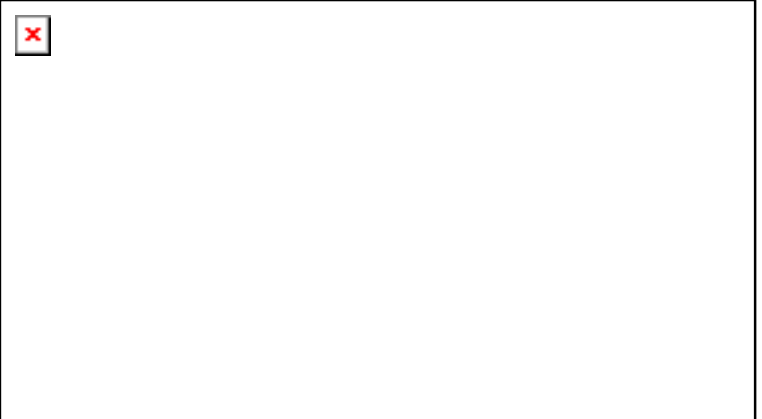

Figura 3. Bairro Várzea, a oeste da BR 471, alocado nas áreas marginais do rio Pardinho é atingido no ano de 2011.Fonte: Defesa Civil de Santa Cruz do Sul.

Na porção central da área urbana, os bairros Santo Inácio, Higienópolis, Centro e os bairros
Avenida e Goiás, que ficam próximos a BR 471, apresentam áreas sujeitas a inundações, contando com intervenções no arroio Jucuri e tributários. Os bairros Bonfim e Margarida, drenados pelo arroio Moinho, também foram verificados problemas em função de inundações.

Estendendo-se da porção leste para noroeste o arroio das Pedras e seus tributários afetam os bairros Arroio Grande (Figura 4), Santo Antônio, Ana Nery, Faxinal, Santa Vitória e Dona Carlota, sendo neste último a localidade conhecida como Beckencamp, atingida seguidamente.

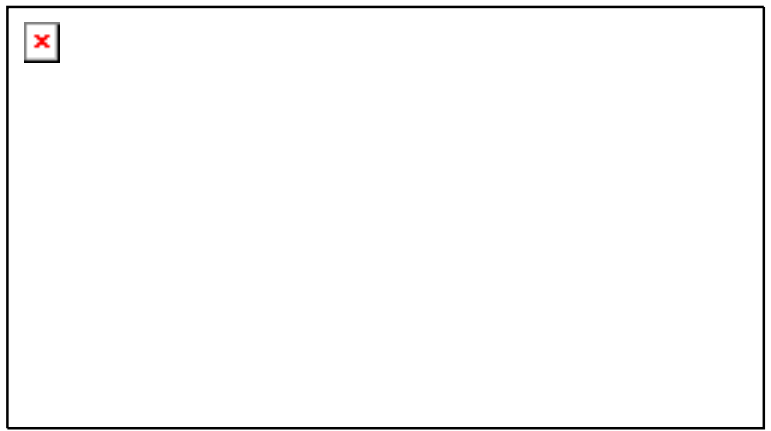

Figura 4. Bairro Arroio Grande apresenta problemas associados à inundações. Fonte: Portal Gaz, 21.11.2013.

Mais ao sul o arroio Levis Pedroso e afluentes estão associados a inundações nos bairros Esmeralda, Rauber e Progresso, sendo que neste o lateamento Eucaliptos, configura uma área seguidamente atingida (Figura 5).

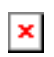

Figura 5. No bairro Progresso, inundação atinge loteamento Eucaliptos. Fonte: Portal Gaz, 21/11/13.

O inventário permitiu identificar a presença de problemas atrelados às inundações em pelo menos 22 bairros (conforme aponta a Figura 6) em diferentes porções da área urbana do município. 


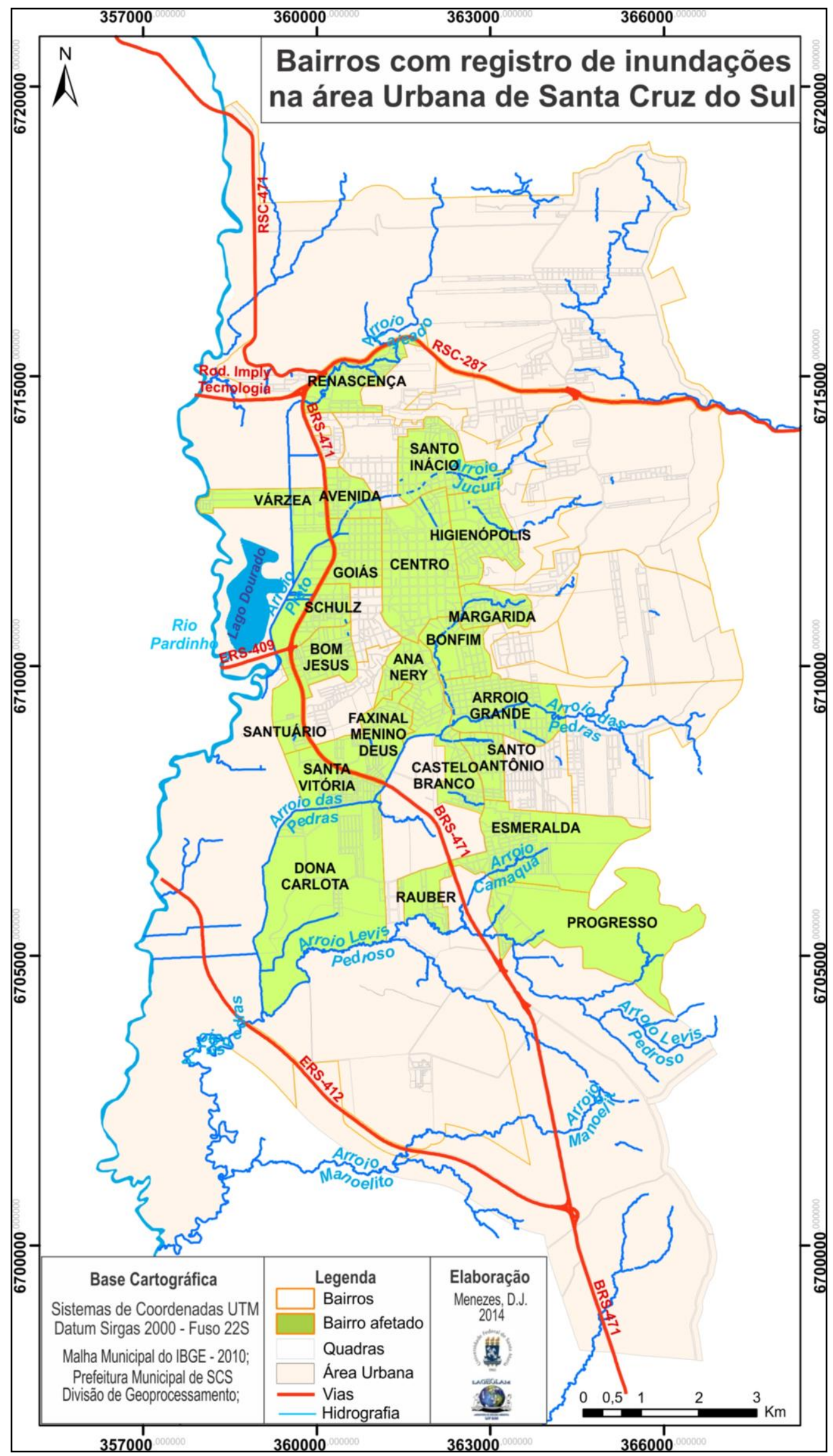

Figura 6. Mapa dos bairros com registro de inundações na área urbana de Santa Cruz do Sul. Organização do autores. 
O levantamento a respeito de dados históricos das inundações ocorridas em Santa Cruz do Sul compreendeu um período de análise de trinta e quatro anos, iniciado em 1980 e estendendo-se até o ano de 2013, apontando trinta e três registros de inundações. Desses registros oito vieram acompanhados de decretos de Situação de Emergência, quando os danos ultrapassam a capacidade do município de enfrentar a situação, sendo uma vez nos anos de 1984, 2005, 2011e 2013 e duas vezes nos anos de 2009 e de 2010. Além disso, em dois eventos foi decretado Estado de Calamidade Pública, ambos nos primeiros meses do ano de 1993, quando as perdas ultrapassam $30 \%$ do PIB municipal.

A Figura 7, que apresenta as datas de registro e os detalhes disponíveis junto à fonte quanto à área afetada ou danos causados (registro de situação de emergência ou de calamidade pública).

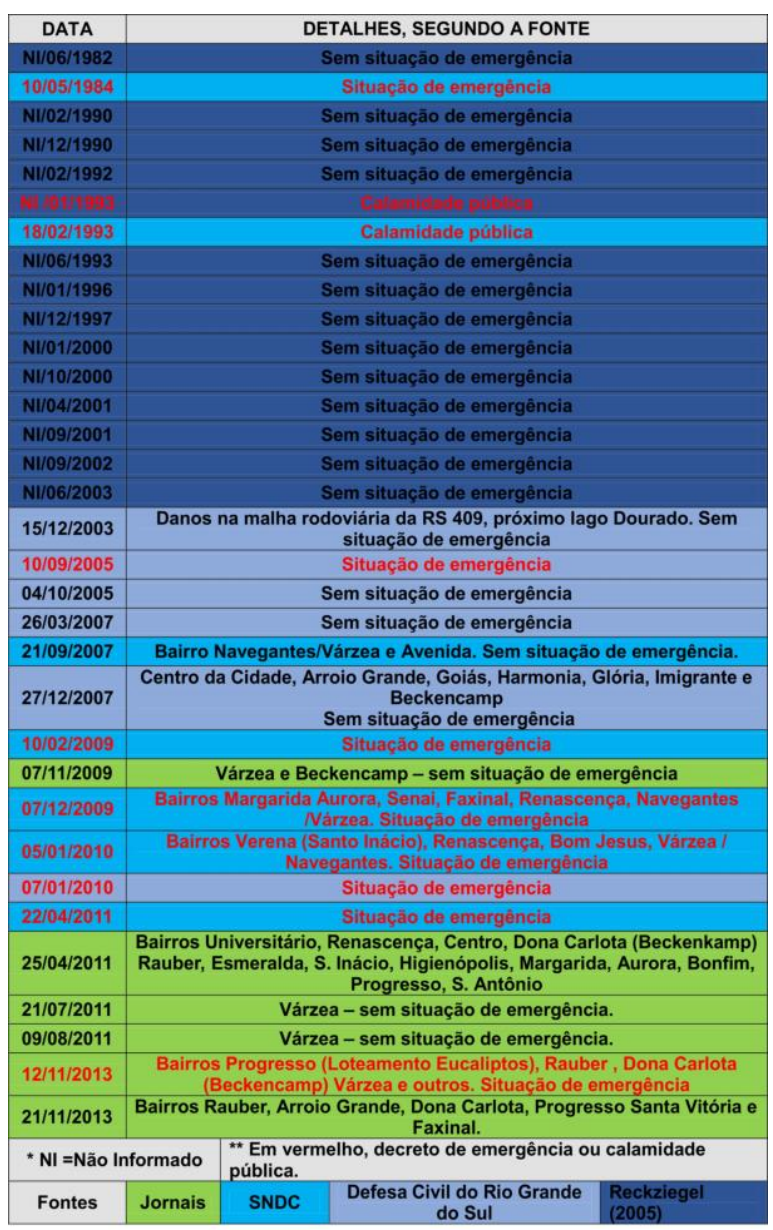

Figura 7. Sistematização dos registros de inundação em Santa Cruz do Sul entre 1980 e 2013. Organização do autores
Quanto à distribuição mensal da ocorrência de inundações (Figura 8), temos um maior número de registros nos meses de verão, entre os meses de dezembro, janeiro e fevereiro, que juntos somam 14 registros do total de 33 levantados. Os meses de dezembro e janeiro marcam um período com altas temperaturas onde as taxas de evaporação e formação de nuvens são elevadas, caracterizando assim chuvas de origem convectiva, que provoca precipitações bruscas e com grande intensidade, causando inundações.

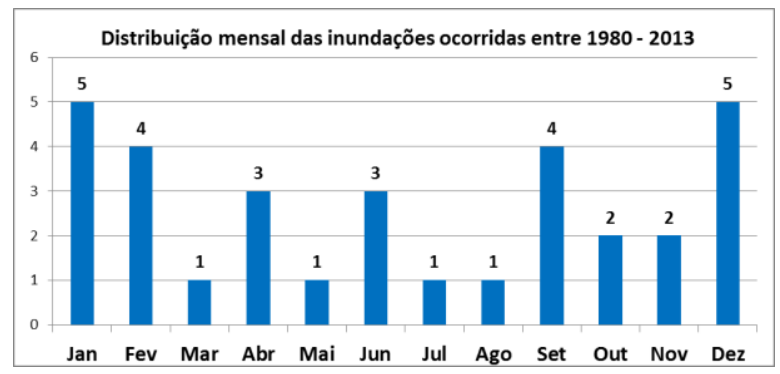

Figura 8. Distribuição mensal das inundações ocorridas entre 1980 e 2013. Organização dos autores.

Em contraponto, os meses de setembro e junho, que registram quatro e três eventos, marcando respectivamente o fim e início do inverno, compreendem um período de transição entre estações e de chuvas frontais.

\section{Conclusões}

Mediante a análise dos registros de inundação na área urbana de Santa Cruz do Sul, evidencia-se que as mesmas causam prejuízos de ordem social e econômica para o município e principalmente à população afetada pelos processos. Tal constatação demanda aos órgãos competentes a adoção de medidas que visem mitigar os prejuízos e perdas que estes eventos possam ocasionar, onde o levantamento destas questões deve instigar o poder público a tomar medidas que visem atenuar este panorama, como também promover a recuperação ou o melhor aproveitamento destas áreas e evitar que novas aglomerados de risco se formem.

Conforme foi observado, uma parcela significativa da área urbana foi estabelecida junto a áreas planas e próximas a drenagens, tendo destaque principalmente o bairro Várzea, alocado em sua totalidade em área suscetível e 
também os bairros Avenida, Santo Inácio Santa Vitória, Progresso e Arroio Grande, com a presença de áreas expressivas.

Pertinente a qualquer análise feita a partir deste levantamento, há de se considerar as diferentes metodologias, graus de detalhamento, entre outros elementos que compõem as fontes que permitiram o mesmo. Tal fato dificultou estabelecer e organizar tipologias e descrições mais precisas quanto a ocorrência destes eventos adversos associados à dinâmica fluvial, ao passo que temos na mesma matriz de informações, algumas já reunidas e organizadas de fontes secundárias, já submetidas a um tratamento pelo pesquisador que a disponibiliza, ao mesmo tempo que temos órgãos oficiais (que obedecem a determinadas diretrizes, quanto ao registro de um evento, para que entre nos dados oficiais e ficando então, disponível para consulta) e ainda a imprensa, o qual o detalhamento e descrição dos eventos e das informações costumam ser muito variados e as vezes imprecisos. Então, considera-se que o registro de eventos adversos deve ser maior que o aqui exposto, em função das condições anteriormente referidas e ainda em função da extensa série temporal que compõem o inventário. Todavia, esta condição não o torna menos funcional, principalmente se considerarmos os últimos registros, que expressam o panorama atual quanto à figuração de áreas de risco em Santa Cruz do Sul.

Este marca algumas áreas com recorrência muito significativa em função de sua suscetibilidade, estando também muitos registros associadas ao processo de evolução e expansão do espaço urbano ou ainda a intervenções mais recentes, que potencializam e recondicionam o local e periodicidade que as drenagens extravasam o seu leito menor.

A organização de um inventário de desastres e a espacialização destas informações permitiu verificar que os eventos associados à dinâmica fluvial são bastante significativos na área estudada, afetando tanto porções a mais tempo consolidadas e também áreas de expansão urbana mais recente e mais precárias quanto à estrutura e saneamento, tal como bairros ao sul da cidade. No entanto, esta condição está associada a uma maior capacidade de intervenção, presença de obras e consequente mitigação de danos que algumas áreas apresentam em relação a outras, potencializando os prejuízos e magnitude em áreas menos privilegiadas do espaço urbano.

\section{Agradecimentos}

Os autores agradecem à Capes e CNPq pelo fomento da pesquisa e à Defesa Civil de Santa Cruz do Sul.

\section{Referências}

AMARAL, R do; RIBEIRO, R. R: Inundação e Enchentes. In TOMINAGA, L. K.; SANTORO, J.; AMARAL, R. (org.). Desastres Naturais: conhecer para prevenir. São Paulo: Instituto Geológico, 2009. p. 39-52

BERTÊ, A. M. A. Problemas ambientais no Rio Grande do Sul. In: VERDUM, R.; BASSO, L. A.; SUERTEGARAY, D. M. A. (Org.). Rio Grande do Sul: paisagens e territórios em transformação. Porto Alegre: Editora da UFRGS, 2004. P 71- 83.

BRASIL. Lei 12.608, de 12 de abril de 2012, disponível em http://www.planalto.gov.br. Acesso em: 27 de maio, 2013.

Ministério da Integração Nacional / Secretaria Nacional de Defesa Civil / Centro Nacional de Gerenciamento de Riscos e Desastres. Anuário brasileiro de desastres naturais: 2012 / Centro Nacional de Gerenciamento de Riscos e Desastres. CENAD, Brasília, 2012. 84 p.

CASTRO, A. L. C. de. Manual de desastres: desastres naturais. Brasília: Ministério da Integração Nacional, 2003. 174 p.

DEFESA CIVIL DE SANTA CRUZ DO SUL. Disponível em: http://defesacivilsantacruz.blogspot.com.br.

DEFESA CIVIL DO ESTADO DO RIO GRANDE DO SUL. Disponível em: http://www.defesacivil.rs.gov.br/.

DIÁRIO REGIONAL. Santa Cruz do Sul, 18 set. 2012. Disponível em: http://www.diarioregionalrs.com.br

EM-DAT: The OFDA/CRED International Disaster Database, Université Catholique de Louvain, Brussels (Belgium); Disponível em: www.emdat.be. 
GAZETA DO SUL, Santa Cruz do Sul, ANO 67, № 75. 25 Abr. 2011. Disponível em: http://www.grupogaz.com.br Santa Cruz do Sul, ANO 69, № 272, 11 Dez. 2013. Disponível em: http://www.grupogaz.com.br

Santa Cruz do Sul, ANO 65, № 293, 05 Jan. 2010. Disponível em: http://www.grupogaz.com.br

Santa Cruz do Sul, ANO 69, № 287, 30 Dez. 2013. Disponível em: http://www.grupogaz.com.br

KOBIYAMA, M. (org.). Prevenção de desastres naturais: conceitos básicos. Curitiba: Ed. Organic Trading, 2006. 109p.

PORTAL GAZ, Gazeta Grupo de Comunicações. Disponível em: http://www.gaz.com.br.

RECKZIEGEL, B. W. (2007). Levantamento dos Desastres desencadeados por Eventos Naturais Adversos no Estado do Rio Grande do Sul no Período de 1980 a 2005. Dissertação (Mestrado em Geografia) - Universidade Federal de Santa Maria, Santa Maria, 2007.

ROBAINA, L. E. de S.; TRENTIN, R. (Org.). Desastres naturais no Rio Grande do Sul. Editora UFSM, Santa Maria, 2013. 496 p.

VEYRET, Y. Os Riscos: O homem como agressor e vítima do Meio Ambiente. Tradução: Dílson Ferreira da Cruz. São Paulo: Contexto, 2007.

ZERO HORA. Porto Alegre, 08 nov. 2009. Disponível em: http://zerohora.clicrbs.com.br. 